\title{
RESPONSE OF COMPOSITE PANELS WITH STIFFNESS GRADIENTS DUE TO STIFFENER TERMINATIONS AND CUTOUTS
}

\author{
Damodar R. Ambur*, James H. Starnes, Jr. ${ }^{\dagger}$, and Carlos G. Dávila ${ }^{\ddagger}$ \\ NASA Langley Research Center \\ Hampton, VA 23681-0001 \\ and \\ Erik A. Phillips ${ }^{\S}$ \\ University of Virginia \\ Charlottesville, VA 22901
}

\begin{abstract}
$\underline{\text { Abstract }}$
The results of an analytical and experimental study of stiffened graphite-epoxy compression panels with terminated stiffeners are presented. The local stress gradients at the stiffener termination location are determined by finite element analysis. Three stiffener termination concepts are evaluated by analysis to determine the stiffener and skin laminate parameters that affect the panel response and failure. The effects of changing local skin laminate definitions, skin reinforcement details, and stiffener termination details on local stress gradients and load-path eccentricities are discussed. Analytical and test results are presented for panels with one terminated stiffener and for panels with one terminated stiffener and two unterminated stiffeners. The effects of a cutout in the skin of a panel with a terminated stiffener is also evaluated to determine the interaction between the stress gradients in the panel due to the cutout and those due to the terminated stiffener. The results of the study indicate that the critical failure modes of the panels initiate at the skin-stiffener interface near the end of the terminated stiffener.
\end{abstract}

\section{Introduction}

It is often necessary to terminate or to "runout" some of the stiffeners in an aircraft structure to satisfy detailed design requirements. Depending on the structural design, stiffeners for a wing structure may terminate at a chord-wise splice, at the forward or rear spar, at a rib, or at a structural discontinuity such as an access hole. An abrupt stiffener termination can cause highly localized bending gradients due to stiffness discontinuities and

\footnotetext{
* Assistant Head, Structural Mechanics Branch. Associate Fellow, ALAA.

${ }^{\dagger}$ Head, Structural Mechanics Branch. Fellow, AIAA.

\# Aerospace Engineer, Structural Mechanics Branch, U. S. Army Vehicle Technology Center. $\$$ School of Civil Engineering, Langley Aerospace Research Summer Scholar.
}

load-path eccentricities. These stiffness discontinuities and load-path eccentricities are similar to those found in laminates with thickness discontinuities or dropped plies (e.g., Refs. 1-3). The local bending gradients generate high local bending and shear stresses in the skin-stiffener interface region that can cause the skin and the stiffener to separate from one another. An experimental and analytical study was conducted ${ }^{4}$ to investigate the failure modes of a graphite-epoxy wingbox cover skin with a terminated hat stiffener in a local region of the skin. A similar graphite-epoxy wing box with impact damage at a terminated stiffener failed at 83 percent of the wing-box design ultimate load when subjected to a bending load. Proper design of these local structural details is essential to prevent unexpected or premature failures in an otherwise well designed structure.

The present paper presents the results of an analytical and experimental study of stiffened graphiteepoxy compression panels with terminated stiffeners. The study was conducted to develop a better understanding of the effects of the stiffness discontinuities and load-path eccentricities associated with this structural detail. The analytical study includes a parametric study that was conducted to determine the effects of two different stiffener termination angles and three combinations of skin and stiffener stiffnesses on the local stress gradients in the stiffener termination region. Based on the results of this parametric study, three different stiffener termination concepts were developed and evaluated analytically and experimentally to determine how effectively the concepts reduce the local stress gradients in the stiffener termination regions. These concepts include stiffeners with discrete flanges and with flanges that are an integral part of the skin. The effects of manufacturing constraints were also considered during the development of the stiffener termination concepts. Two stiffener termination concepts with different stiffener flange details were selected for further evaluation in different panel configurations with three stiffeners. One of these threestiffener panel configurations represents a panel with the center stiffener terminated at a wing rib or at a fuselage

Copyrigbt 1997 by une Americon lastiture of Aeronautics and Aswonautics. Inc. No copynigbt is aseerved in the Unived Soutes under Tiste 17, U.S. Code. The US. Govemnent has a myalty.frce boense to exercise all rights under be copynight claimed berein for govermental purposes. N other rights ate reserved by the copyright owner. 
frame location. Another panel configuration represents a panel with the center stiffener terminated at a wing fuel-cell location or at a cutout location. The paper presents a summary of the parametric studies for panels with one stiffener, and the experimental and analysis results for panels with one and with three stiffeners.

\section{Concepts, Analytical Models and Analysis Codes}

Detailed finite element models were developed for all of the panels considered in this study. The models include all stiffener termination details, skin reinforcement details, and stiffener flange reinforcement details for all of the concepts evaluated. During the course of this study, three different finite element analysis codes were used for the analytical studies.

The initial parametric studies were conducted with the DIAL finite element code. ${ }^{5} \quad$ Linear stress analysis results from the initial analytical studies were used to determine the stiffener termination angle for the panels, and to establish a baseline configuration for subsequent comparisons. The results of these studies are presented in the Results and Discussion section of the present paper. The baseline configuration is shown in Figure 1(a), and the DIAL finite element model for this configuration is shown in Figure 1(b). In this model the skin, stiffener web, stiffener flange, and the parts of the panel remote from the stiffener termination region are modeled with quadrilateral shear-deformable plate elements. The skin in the region around the end of the stiffener termination is modeled using quadratic threedimensional solid elements. Displacement compatibility between the solid elements and the plate elements in the skin and the stiffener regions are enforced with multi-point constraint equations.

The results of the initial parametric studies were also used to identify variations of the baseline configuration that could be used to study the effects of changing design parameters of the local stiffener termination details. The axial stiffness of the skin laminate for the baseline stiffener termination configuration is 33 percent less stiff than the stiffener. Two additional skin laminates were considered to determine the effect of varying skin laminate on the inplane and through-the-thickness stresses in the stiffener termination region. The stiffener properties are the same as the baseline for these skin laminate variations. The first skin laminate variation has an axial stiffness that is approximately equal to the axial stiffness of the stiffener. This skin laminate is referred to herein as the "balanced skin" laminate. The second skin laminate variation has an axial stiffness that is greater than the axial stiffness of the stiffener. This skin laminate is referred to herein as the "hard skin" laminate.
In addition, the results of the initial parametric studies were used to identify other stiffener termination concepts with different local detail features. Three stiffener termination concepts were developed from these results which suggested that the magnitudes of the stresses in the stiffener termination region could be reduced by adding material to the skin. These stiffener termination concepts are referred to herein as Concepts 1, 2 and 3. Concept 1 is illustrated in Figure 2(a). This concept has bridge plates that are bolted to the panel over the stiffener flange and the end plate, and these bridge plates extend well beyond the local stiffener termination location. The bridge plates reduce all stress magnitudes in the stiffener runout region significantly. Concept 2 is shown in Figure 2(b). The skin for this concept is tapered at the stiffener termination and an end plate is used to secure the terminated stiffener flange to the tapered skin region. The thickness and length of the taper were determined by performing parametric studies using a three-dimensional solid finite element model. For this concept, the tapered skin, terminated stiffener and end plate are cocured in the fabrication process. The tapered skin reduces the load-path eccentricity for this concept. Concept 3 is shown in Figure 2(c). This concept is a derivative of Concept 2 where the tapered skin shown in Figure 2(b) replaced by a secondarily bonded tapered reinforcing plate. This concept has the potential for a lower manufacturing cost than the other concepts. The details of the tapered skin are shown in Figure 2(d).

The three stiffener termination concepts were evaluated with one- and three-stiffener panel configurations. The one- and three stiffener panel configurations were modeled in detail with PATRAN. ${ }^{6}$ These models were developed using nine-node ANS shear deformable elements. The STAGS finite element code $^{7}$ was used to conduct buckling and nonlinear structural analyses and the ABAQUS finite element $\operatorname{code}^{8}$ was used to conduct a quasi-three-dimensional local stress analyses of the interlaminar stresses in the stiffener termination region.

\section{One-Stiffener Panel Configurations}

A typical finite element model of a one-stiffener panel configuration is shown in Figure 3(a) for stiffener termination Concept 2. To help understand the interlaminar stress distributions that cause failure in the panel, an element-layered finite element model was developed to determine the interlaminar stresses between the skin-stiffener flange interface and stiffener flange laminate-stiffener blade interfaces. The layered finite element model is shown in Figure 3(b), and consists of four-node thick shell elements and 5792 nodes. The model has over 4,000 multi-point-constraint equations that enforce displacement compatibility between the 
layers of the stiffener and at the interfaces of the stiffener flange and the skin.

\section{Three-Stiffener Panel Configurations}

Three three-stiffener panel configurations were considered in this study to help evaluate the stiffener termination concepts and to simulate several practical applications. These three-stiffener panel configurations are referred to herein as Panels A, B and C. The finite element models for the three three-stiffener panel configurations are shown in Figure 4. Panel $A$ is illustrated in Figure 4(a). This structural configuration is representative of stiffener termination detail at a rib location for fuel-filled wing where the rib cannot be penetrated. This panel simulates a stiffener that is terminated at a rib cap. The length of the bridge plates for Panel A have been extended further away from the rib location compared to the single-stiffener specimen in order to minimize any interaction of the stiffener flange and the skin when the panel deforms when loaded. The model for Panel A consists of four-node shell elements. Panel B is shown in Figure 4(b). This panel simulates a stiffener that is terminated at a fuel tank. Panel $C$ is shown in Figure 4(c). This panel simulates a stiffener that is terminated at an access port or cutout. The models for Panels B and C consist of nine-node ANS shear deformable elements. The model for Panel A has 28,000 degrees of freedom, and the models for Panels B and $C$ have 32,100 and 55,355 degrees of freedom, respectively.

\section{Test Specimens and Tests}

One-stiffener and three-stiffener panel specimens were fabricated and tested to help evaluate the stiffener termination concepts. All specimens were fabricated from Hercules, Inc. AS4/3501-6 graphite-epoxy preimpregnated tape material following the resin manufacturer's recommended processing procedure. The nominal thickness of the AS4/3501-6 preimpregnated tape material used for all the structural elements is 0.005 in., and the properties of the material are presented in Table 1. The ply orientations for the skin, stiffener flange, stiffener web, rib flange or end plate laminates are $[ \pm 45 / \mp 45 / 90 / 02 / 90 / \pm 45 / \mp 45 / \pm 45]_{\mathrm{S}}$, $[ \pm 45 / \mp 45 / 90 / 0]_{s},[ \pm 45 / \mp 45 / 90 / 04 / 90 / 04 / 90 / 04 / \pm 45 /$

$\left.0_{2}\right]_{S}$, and $[ \pm 45 / \mp 45 / 90 / 0]_{S}$, respectively. These structural element ply orientations are typical of those used in lightly-loaded parts of a transport aircraft wing cover panel. The "balanced skin" and "hard skin" laminates are $\left[ \pm 45 / \mp 45 / 0 / 90 / 0 / 45_{\mathrm{fab}}\right]_{\mathrm{S}}$ and $\left[ \pm 45 / \mp 45 / 0 / 90 / 0 / 0_{\text {fab }}\right]_{S}$, respectively. The subscript "fab" refers to a woven fabric for of the graphite-epoxy material. All one-stiffener panel configuration specimens are 18-inches long and 10-inches wide.

Test specimens for the three-stiffener panel configurations with stiffener termination Concepts 1 and 3 are shown in Figure 5. The specimen shown in Figure $5(a)$ is the Panel A configuration and the stiffener terminations occur on either side of a simulated rib location. The specimen shown in Figure $5(\mathrm{~b})$ is the Panel B configuration. This panel configuration represents a wing cover panel or a fuselage panel with a stiffener terminated to accommodate a cutout. Panel C is similar to Panel B but it has a 4-in.-diameter cutout in the skin on the other side of the simulated rib station from the terminated stiffener. Panel $\mathrm{C}$ is intended to study the influence of an access hole on the stress distributions in the stiffener termination region. All three-stiffener panel specimens are 30-inches long and 16-inches wide.

The stiffener termination details for the threestiffener panel configurations were designed so that the maximum values of the strains in the stiffener termination region are below the failure strains for this material when the far-field design strain of the specimen is equal to $4,000 \mu \mathrm{in}$./in. The panels were also required to be buckling resistant before failure. The thickness of the skin laminate for Panel A was increased in the region between the stiffeners opposite to the terminated stiffener to satisfy this buckling constraint. The laminate for this additional skin thickness is the same as for the stiffened panel skin.

All specimens were quasi-statically tested in uniaxial compression to failure in a 300-kip hydraulic test machine. Electrical resistance strain gages were used to measure the strains in the specimens, and direct current differential transducers were used to measure the displacements of the specimens during the tests. All test data were recorded electronically by a multi-channel data acquisition system that recorded data from all data channels once each second. The unstiffened side of each specimen was painted white so that a shadow moiré interferometric system could be used to observe the outof-plane deflection patterns of the painted surface. The shadow moiré interferometric patterns were reconded photographically and on video tape during each test.

The specimens were tested with potted end conditions to simulate "near clamped" boundary conditions, and knife-edge supports were used along the longitudinal edges of the specimens to simulate simplysupported boundary conditions. In addition to these boundary conditions, the three-stiffener specimens were constrained so they would not move in the out-of-plane direction at the simulated rib location to simulate the conditions imposed by a wing rib. 


\section{$\underline{\text { Results and Discussion }}$}

Parametric Study Results

Baseline Stiffener Termination Angle. The stiffener termination angle was selected based on linear stress analysis results for the baseline stiffener termination configuration shown in Figure 1(a). The stress results for terminated stiffeners with stiffener termination angles of $30^{\circ}$ and $45^{\circ}$ are shown in Figure 6 for an applied uniform end-shortening displacement of 0.005 inches. The through-the-thickness transverse shear stress magnitudes for these termination angles are shown in Figure $6(\mathrm{~b})$. The magnitude of the transverse

shear stress $\tau_{x z}$ for the $45^{\circ}$ termination angle is 37 percent greater than that for the $30^{\circ}$ termination angle.

The axial strain and transverse normal stress $\sigma_{z z}$ magnitudes are not significantly different for the two termination angles. Also, the load from the terminated stiffener is transferred to the skin by inplane shear over a longer distance for the stiffener with the $30^{\circ}$ stiffener termination angle than for the specimen with a $45^{\circ}$ stiffener termination angle. These results indicate that the inplane shear stress magnitudes for a given stiffener with a $45^{\circ}$ stiffener termination angle are significantly higher than those for a stiffener with a $30^{\circ}$ stiffener termination angle, and as a result, the $30^{\circ}$ stiffener termination angle was chosen as the baseline configuration in the present study.

Effects of Skin Laminate Stiffness. The linear stress results for stiffener termination configurations with the baseline, "balanced" and "hard" skins are shown in Figure 7 for an applied uniform end-shortening displacement of 0.005 inches. These results indicate that the magnitudes of the axial and transverse normal stresses decrease as the axial stiffness of the skin increases. As the stiffness of the skin increases relative to the stiffness of the stiffener, the line of action of the resultant force of the panel cross section shifts closer to the skin, and the stiffer skin supports a larger percentage of the total applied load than the stiffener. The shift of the line of action of the resultant force towards the skin decreases the eccentricity in the load path and decreases the magnitude of the local bending gradient at the stiffener termination. As the bending gradient is decreased, the axial and transverse normal stress magnitudes are also decreased. The shear stress magnitudes are also decreased since the load carried by the relatively soft stiffener is lower in magnitude and can be transferred to the skin more gradually if the stiffener termination angle is at a $30^{\circ}$ angle to the skin surface.

\section{One-Stiffener Panel Configurations}

The end-shortening and out-of-plane displacement results for the three one-stiffener panels with stiffener termination Concepts 1,2 and 3 are summarized in Figure 8 . The response for panels with stiffener termination Concepts 1 and 2 have a higher degree of nonlinearity than the response for the panel with stiffener termination Concept 3 as the load is increased. The failure load for the panel with stiffener termination Concept 1 is 47 kips which is the greatest value of the failure loads of the panels. The measured axial strain distributions along the length and width of the specimen with stiffener termination Concept 1 are shown in Figure 9. The strain magnitudes decrease as the distance from the stiffener termination increases in both the specimen length and width directions which is consistent with the general trend of the analytical results from the initial parametric studies. The measured strain results for the specimen with stiffener termination Concept 2 are compared with analytical results in Figure 10. The strain results obtained from a nonlinear analysis for points $C$ and $E$ on the tapered skin confirm the linear nature of the response for this specimen, and the analysis results for strains compare well with the experimental results.

The out-of-plane deflections and failure mode for the one-stiffener specimen with stiffener termination Concept 1 is shown in Figure 11 . This specimen deforms significantly in the out-of-plane direction which causes the bridge plate to push into the stiffener flange which causes the stiffener flange to separate from the skin. The out-of-plane deformation contours obtained from shadow moiré interferometry are shown in the figure for a compression load of $42.56 \mathrm{kips}$, and the failed specimen is also shown in the figure. The failure of the specimen with stiffener termination Concept 2 was caused by the delamination of the stiffener flange in the vicinity of the end of the terminated stiffener. The interlaminar stresses near the end of the stiffener termination were determined from the analysis results by distributing the nodal tractions associated with the multi-point constraints over the corresponding element areas. These nodal tractions are obtained by summing the element internal nodal forces from all the elements that share a given node. Since the multi-point constraints enforce constraints on the $u, v$, w displacement components, they cause forces in the three coordinate directions. The corresponding stresses are approximated as the force divided by a quarter of the sum of the element areas. The quadratic failure delamination index demonstrated in Ref. 9 is computed from the interlaminar stresses and is shown in Figure 12. The expression for the delamination index is given by 


$$
F I=\sqrt{\left(\frac{\sigma_{z}}{Z^{T}}\right)^{2}+\left(\frac{\tau_{x z}}{Z^{s}}\right)^{2}+\left(\frac{\tau_{y z}}{Z^{s}}\right)^{2}}
$$

The tensile normal stresses $\left(\sigma_{z}\right)$ are used only when they are tensile which aid the failure process. The failure stress values assumed for the transverse normal and transverse shear stresses are $7.5 \mathrm{ksi}$ and $13.5 \mathrm{ksi}$, respectively. These results suggest that high interlaminar stresses occur in the region of the end of the terminated stiffener. These high values of interlaminar stresses occur as a result of the process of transferring the load in the stiffener to the skin, and this stress state most likely caused the specimen to fail.

\section{Three-Stiffener Panel Configurations}

The results of buckling analyses the three threestiffener panel configurations indicate that the buckling loads of the specimens are $218.3,226$, and 218 kips, respectively. Since the cutout in Panel C is located at the crest of the buckled skin between the stiffeners, it does not result in a significant reduction in the buckling load of the panel or a change in the buckling mode shape. The end-shortening displacement and out-ofplane displacement results for the three-stiffener panels are summarized in Figure 13. The nonlinearity in the response of these panels is similar to that for the onestiffener specimens with the same stiffener termination detail.

Typical strain results for Panel A are shown in Figure 14. Strain gages 1 and 3 represent stiffener strains and strain gage 5 represents a skin strain. The strain distribution along the surface of the stiffener termination is represented by strain gages 36,40 , and 44. The strain gages on the stiffener in the termination region indicate that failure of the specimen initiated at 120 kips. The results indicate that the specimen supports additional load after failure initiation and fails at a load of 157 kips. The strain results for strain gage 5 at failure indicate that the far-field strain exceeds 4,000 $\mu$ in./in. at specimen failure. The failure mode for Panel $A$ is shown Figure 15. The results from strain gages indicate that the failure of this panel appears to have initiated at the stiffener flange near the end of the bridge plate. The stiffener flange separated from the skin at this location. This local skin-stiffener separation caused the skin to deform out-of-plane and to separate from the remaining stiffeners. After the skin separated from the stiffeners, the load was transferred to the stiffeners which caused the stiffeners to cripple and fail the specimen. There are no indications of any additional failure in the region of stiffener termination suggesting that this concept satisfied the design requirements. The measured far-field strain for this panel is approximately $4,200 \mu \mathrm{in}$./in. at failure.
Analytical axial strain contour results for Panels B and Panel $\mathrm{C}$ at the failure initiation loads are shown in Figure 16. The maximum value of the strain results is less than $4,500 \mu$ in./in., and the failure of these panels is unlikely to have been caused by the strains exceeding the allowable axial strain value. Analytical inplane shear stress contour results for these panels are shown in Figure 17. These results indicate that the stress magnitudes for Panels B and C are greater than 5,250 $\mathrm{lb} / \mathrm{in}$. The stress concentrations at the ends of the terminated stiffeners are caused by the load that is transferred by the shear stresses between the skin and the stiffener. These shear stresses have the potential for initiating the failure for these three-stiffener panel specimens. The experimental out-of-plane displacement contour results for the Panel $\mathrm{C}$ specimen are shown in Figure 18 by the moiré interferometry fringe patterns from the test. The moire fringe pattern results shown in Figure 18(a) indicate that the displacement are localized in the stiffener termination region as the compression load approaches 90.2 kips. The skin reinforcement in the cutout region separated from the skin at a load of 96.1 kips. Since the skin reinforcement extends to the stiffener termination region, a considerable amount of load redistribution occurs in the panel which causes the panel to deform out-of-plane in the stiffener termination region as shown in Figure 18(b). The panel eventually failed at a load of 112.7 kips. The far-field strain magnitudes for this panel design reached $3,925 \mu \mathrm{in}$./in. at the failure load. The three-stiffener Panel B without the cutout failed at a load of 120 kips in a mode similar to Panel C. The far-field strain value at failure for this panel was approximately $4,100 \mu \mathrm{in} . / \mathrm{in}$. The analytical and experimental axial strain results for Panel $C$ are compared in Figure 19. The initial failure occurred at a load of 96.1 kips as indicated by a discontinuity in the strain gage results at this value of the load. The comparison between the experimental and analytical axial strain results is good until the initial failure occurs which suggests that the analysis approach used in this study is adequate for predicting the panel response. Although the stiffener termination concept used for Panels B and C appears to have performed well, the integration of the reinforced skin region with the panel concepts needs to be improved to avoid premature failure of the structure.

\section{Concluding Remarks}

The results of an analytical and experimental study of stiffened graphite-epoxy compression panels with terminated stiffeners are presented. Three different stiffener termination concepts have been evaluated analytically and experimentally in the study. One of the stiffener termination concepts is based on a reinforcing strap that connects the terminated stiffener flange to the surrounding skin. This concept minimizes the effects 
of the local bending caused by the stiffness discontinuities and load-path eccentricity associated with the terminated stiffener. The other two stiffener termination concepts are based on tapered reinforcements of the panel skin in the region of the terminated stiffener. All specimens tested and analyzed in the study exhibited some degree of nonlinear behavior. One of the stiffener termination concepts supported a greater load at failure than the other two concepts. The failure mode for the specimen with this stiffener termination concept initiated at the end of the local reinforcing strap that connected the terminated stiffener flange to the skin near the end of the terminated stiffener. The failure mode of specimens with the other stiffener termination concepts occurred at the end of the terminated stiffener where the highest shear stress magnitudes are located. The failure mode for the specimen with a reinforced skin region was caused by the separation of the bonded skin reinforcement from the rest of the specimen. The results of the study indicate that the critical failure modes of the panels initiate at the skin-stiffener interface near the end of the terminated stiffener. The effects of a cutout in the skin of a panel with a terminated stiffener was also evaluated to determine the interaction between the stress gradients in the panel due to the cutout and those due to the terminated stiffener. The results indicated that the cutout had little effect on the buckling load or the failure load of the panel. The far-field strains of the panels at failure are approximately equal to the design strain value of $4,000 \mu \mathrm{in} . / \mathrm{in}$. indicating that the concepts satisfied the design requirement.

\section{References}

1. Kemp, B. L., and Johnson, E. R., "Response and Failure Analysis of a Graphite-Epoxy laminate Containing Terminating Internal Plies," AIAA Paper 85-0608, April 1985.

2. Curry, J. M., Johnson, E. R., and Starnes, J. H., Jr., "Effect of Dropped Plies on the Strength of Graphite-Epoxy Laminates," AIAA Joumal, Vol. 30, No. 2, February 1992, pp. 449-456.

3. Ambur, D. R., Starnes, J. H., Jr., and Waters, W. A., "Effects of Low-Speed Impact Damage on the Compression Strength of a Graphite-Epoxy Laminated
Plate with a Skewed Thickness Taper," AIAA paper 94-1403, April 1994.

4. Davis, D. D., Jr., Farley, G. L., Ambur, D. R., Davis, R. C., Shuart, M. J., Wang, J. T., and Lotts, C. G., "An Analytically Designed Sub-Component Test to Reproduce the Failure of a Composite Wing Box Beam," ALAA Paper No. 93-1344, April 1993.

5. Anon., "DIAL Structural Analysis system User Manual," Lockheed Missiles and Space Company, Inc., Version L3D3, August 1, 1991.

6. Anon., "PATRAN Plus User Manual - Release 2.4," PDA Engineering, Publication Number 2191023 , September 1989.

7. Brogan, F. A., Rankin, C. C., and Cabiness, H. D., "STAGS User Manual," Lockheed Palo Alto Research Laboratory, Report LMSC P032594, 1994.

8. Anon.: “ABAQUS/Standard User's Manual, Vols. 1-2," Hibbitt, Carlson and Sorenson, Inc., Pawtucket, $\mathrm{RI}, 1995$.

9. Dávila, C. G., and Johnson, E. R., "Analysis of Delamination Initiation in Postbuckled Dropped-Ply Laminates," AIAA Journal, Vol. 31, No. 4, April 1993, pp. 721-727.

Table 1. Mechanical properties for AS4/3501-6 graphite-epoxy preimpregnated tape material.

\begin{tabular}{ll}
\hline \hline & \\
Longitudinal modulus, $\mathrm{E}_{1}, \mathrm{Msi}$ & 18.50 \\
Transverse modulus, $\mathrm{E}_{2}, \mathrm{Msi}$ & 1.64 \\
In-plane shear modulus, $\mathrm{G}_{12}, \mathrm{Msi}$ & 0.87 \\
Transverse shear modulus, $\mathrm{G}_{23}, \mathrm{Msi}$ & 0.49 \\
Transverse shear modulus, $\mathrm{G}_{13}, \mathrm{Msi}$ & 0.87 \\
Major Poisson's ratio, $\mathrm{v}_{12}$ & 0.3 \\
\hline \hline
\end{tabular}



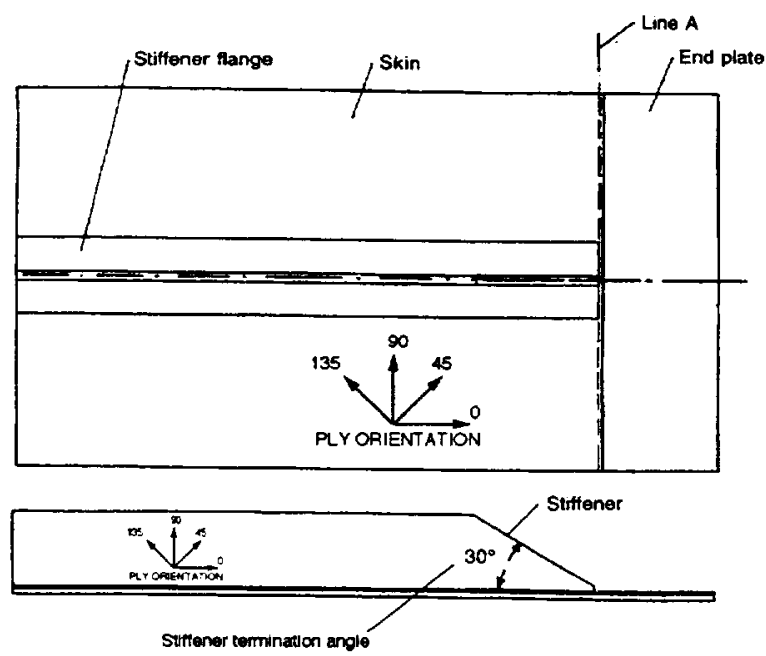

a. Baseline stiffener termination concept.

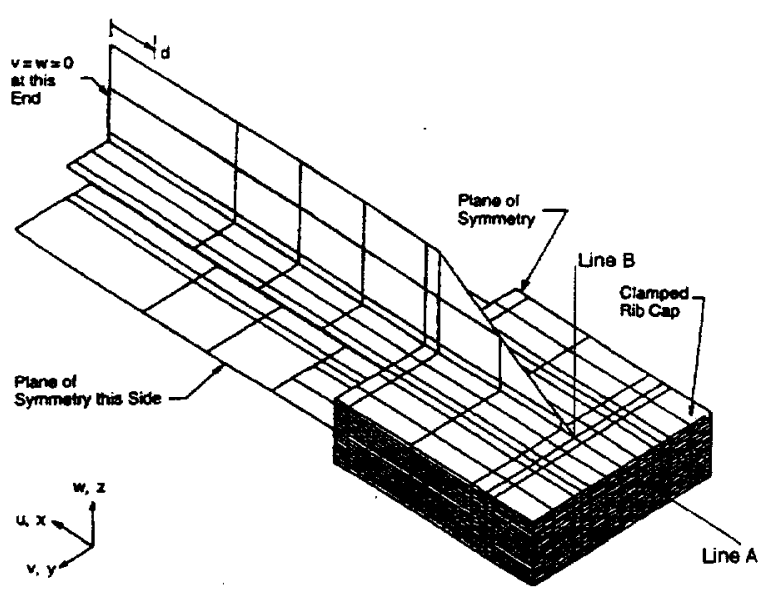

b. Finite element model.

Figure 1. Baseline stiffener termination configuration.

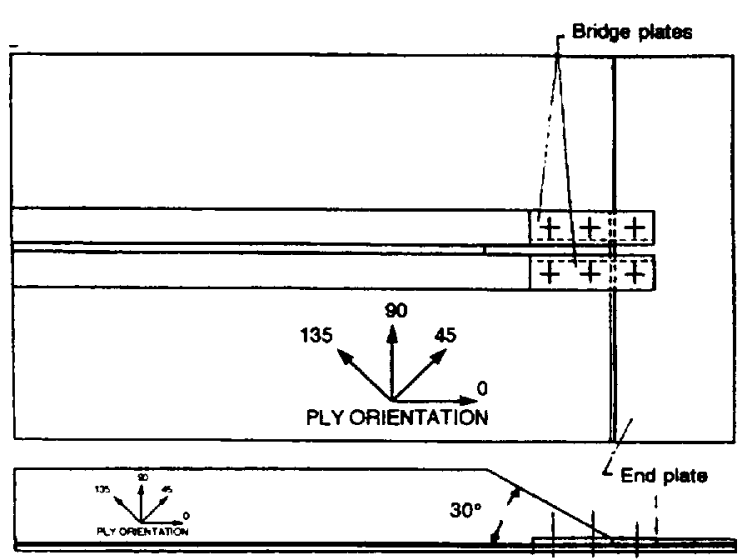

a. Concept with bolted bridge plates - Concept 1 .

Figure 2. The stiffener termination concepts.

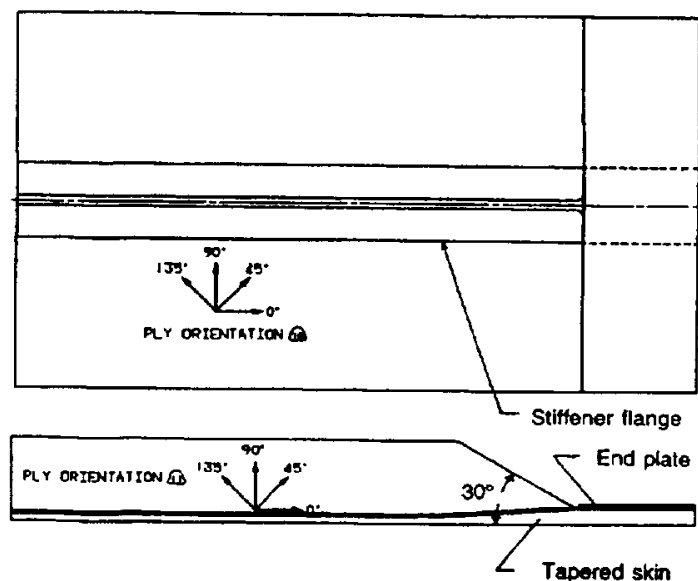

b. Concept with cocured tapered skin - Concept 2 .



c. Concept with bonded tapered skin - Concept 3 .

0.36 in. thick

0.18 in. thick

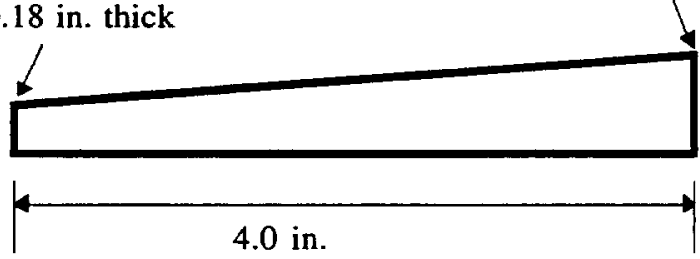

d. Tapered laminate details.

Figure 2. Concluded. 


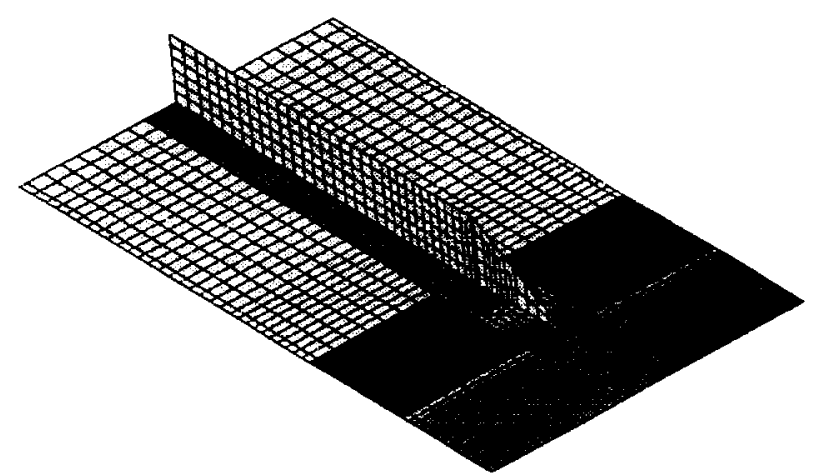

a. Basic finite element model.

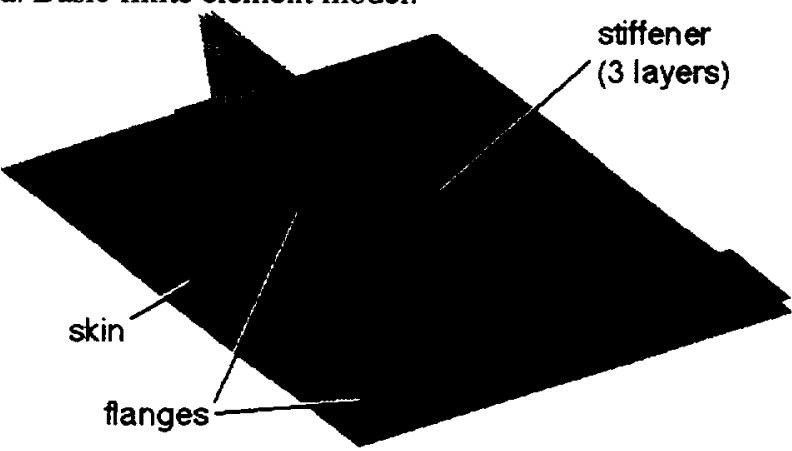

b. Element-layered model.

Figure 3. Finite element models for Concept 2.

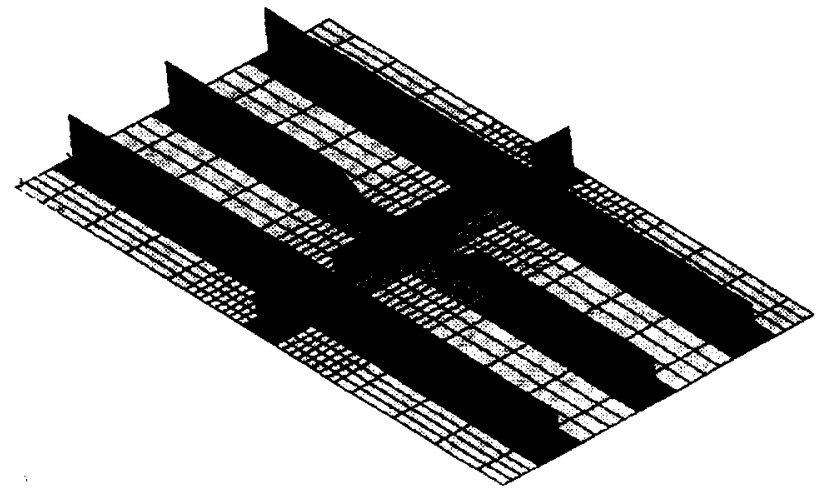

a. Finite element model for Panel A.

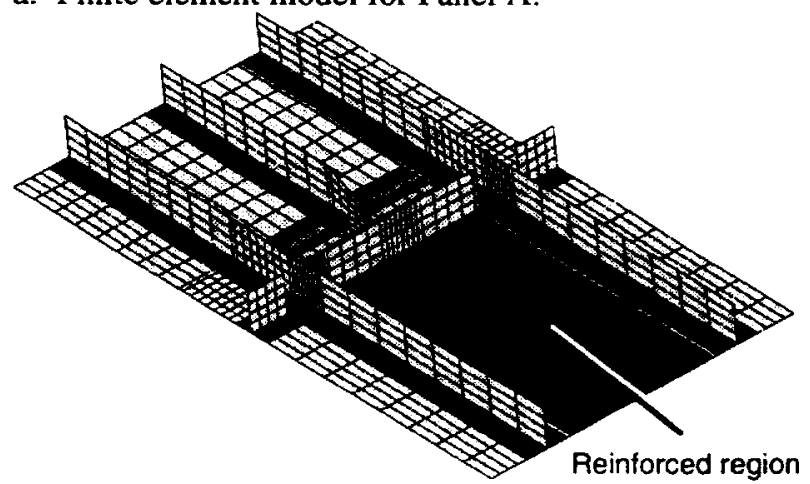

b. Finite element model for Panel B.

Figure 4. Finite element models for the three-stiffener panlels.

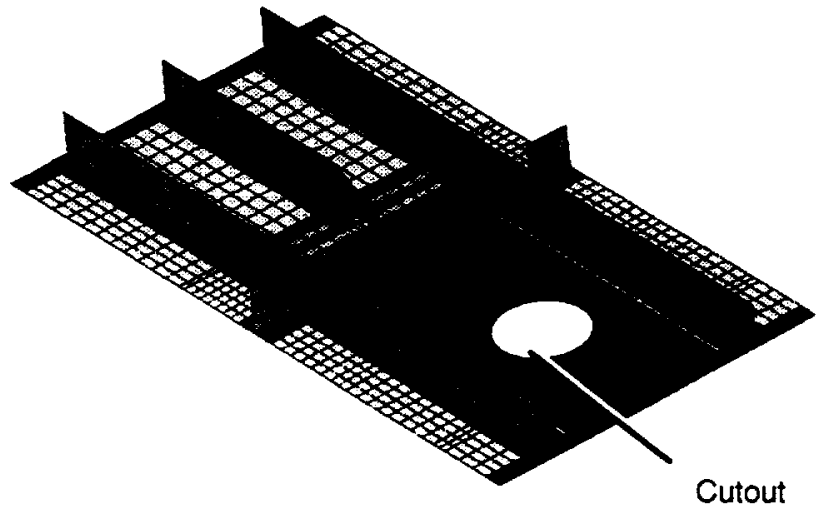

c. Finite element model for Panel C.

Figure 4. Concluded.

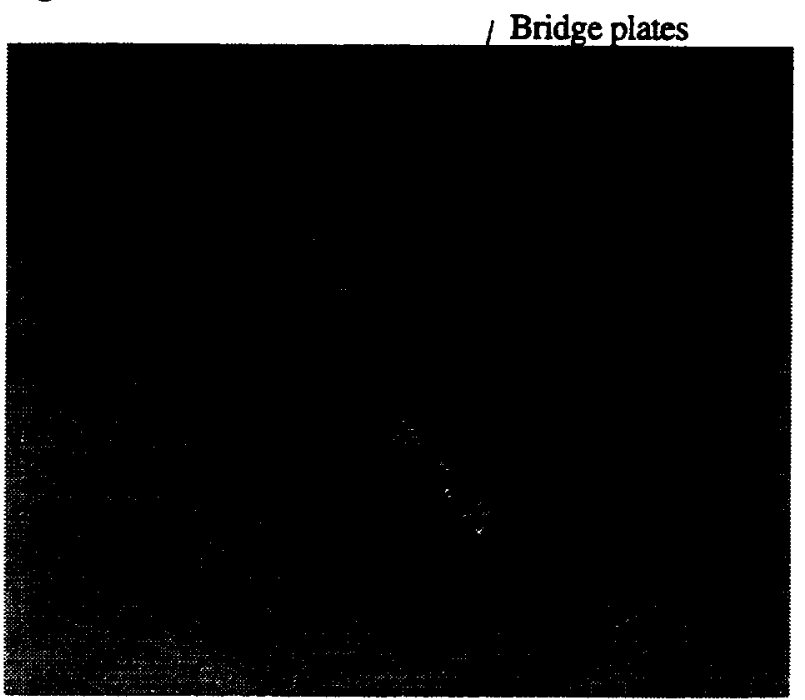

a. Panel A.

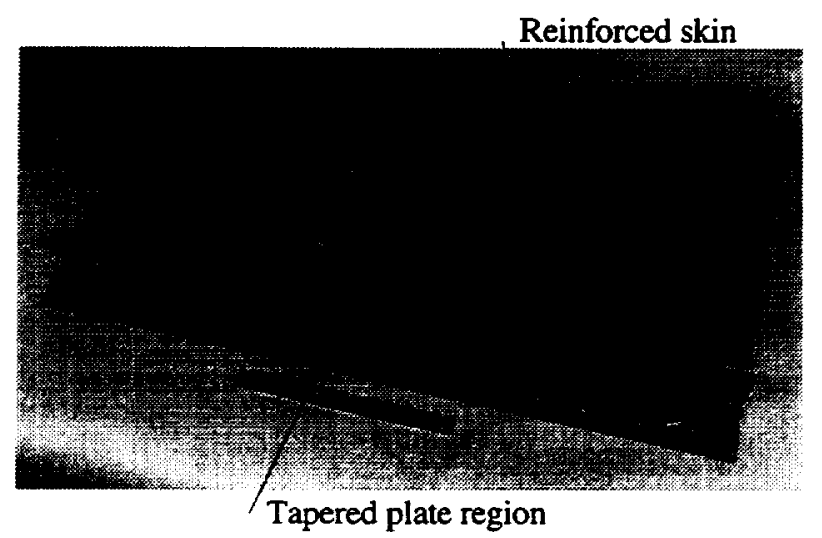

b. Panel B.

Figure 5. Photographs of two three-stiffener panel configurations with different stiffener termination concepts. 

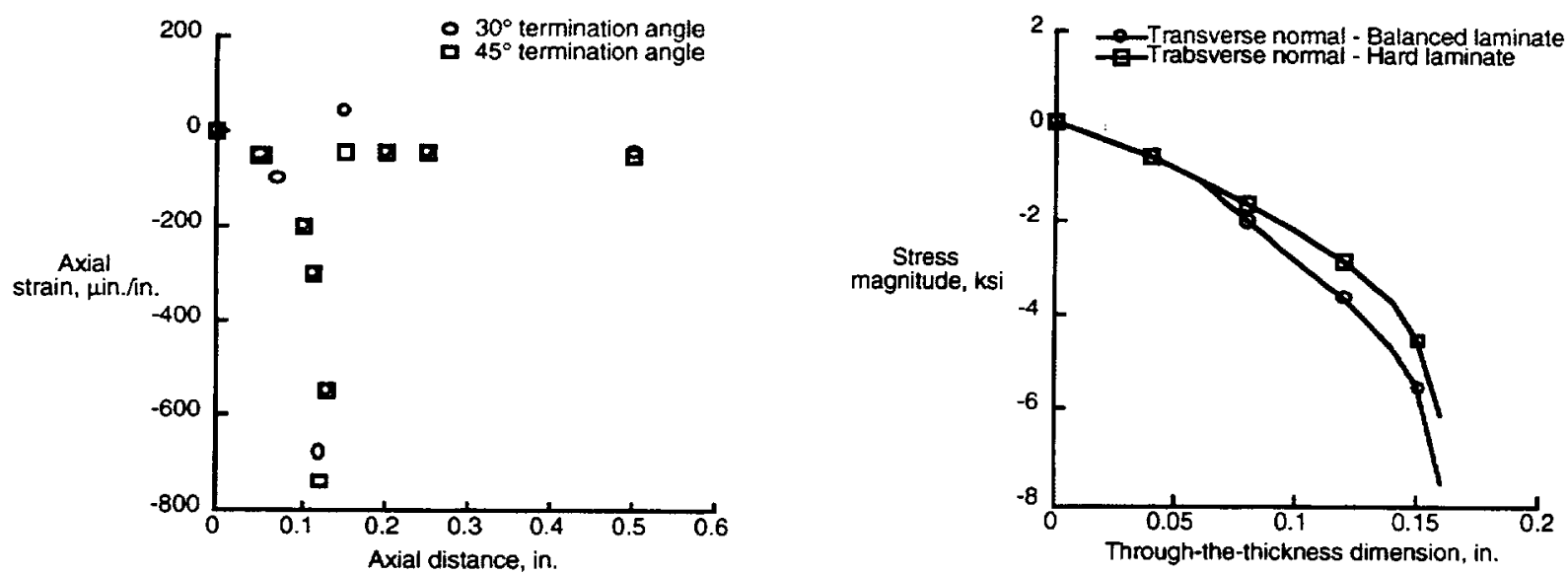

a. Axial strain results along specimen axis (along Line $\mathrm{A} \mathrm{in}_{\mathrm{b}}$. Stress gradient through the skin thickness (along in Figure 1(b)).

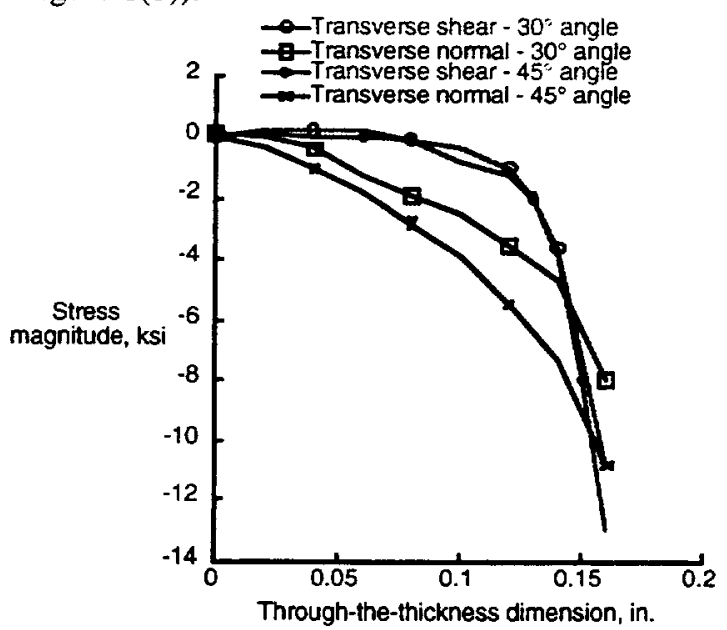

b. Stress gradient through the skin thickness (along Line B in Fig. 1(b)).

Figure 6. Comparison of analysis results for two baseline stiffener termination configurations with $30^{\circ}$ and $45^{\circ}$ stiffener termination angles.

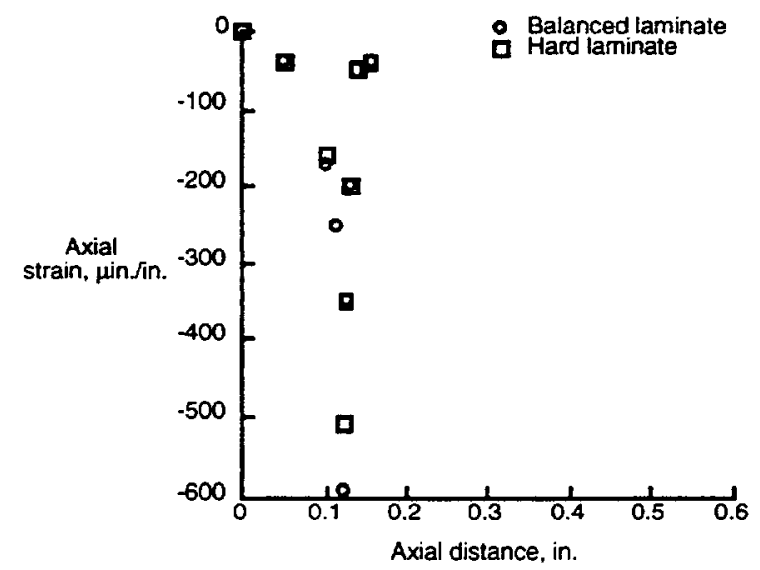

a. Axial strain results along slongitudinal axis (along Line A in Figure 1(b)).

Figure 7. Comparison of analysis results for two baseline stiffener termination configurations with "balanced" and "hard" skin layups. Line B in Fig. 1(b)).

Figure 7. Concluded.

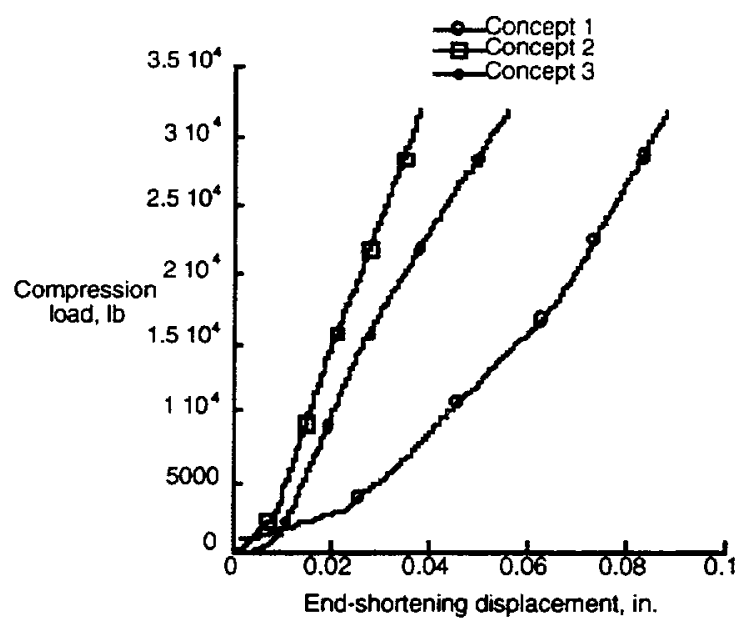

a. End-shortening displacement results.

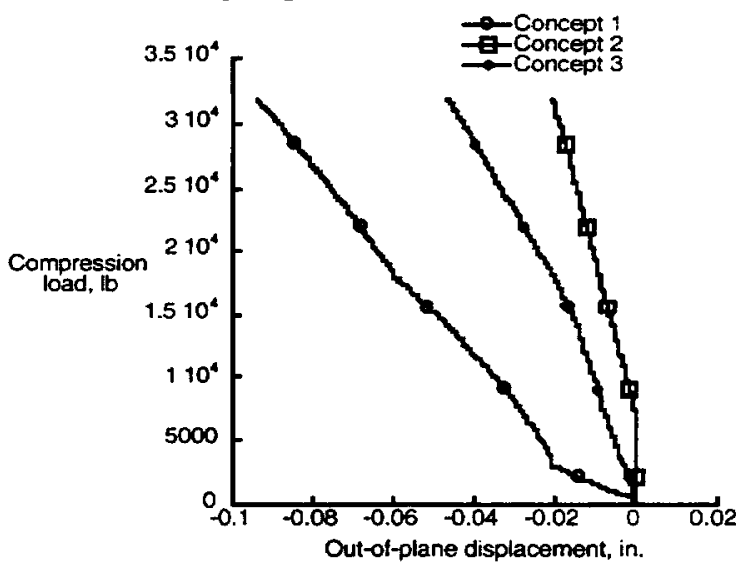

b. Out-of-plane displacement results.

Figure 8. Summary of displacement results for stiffener termination Concepts 1-3. 


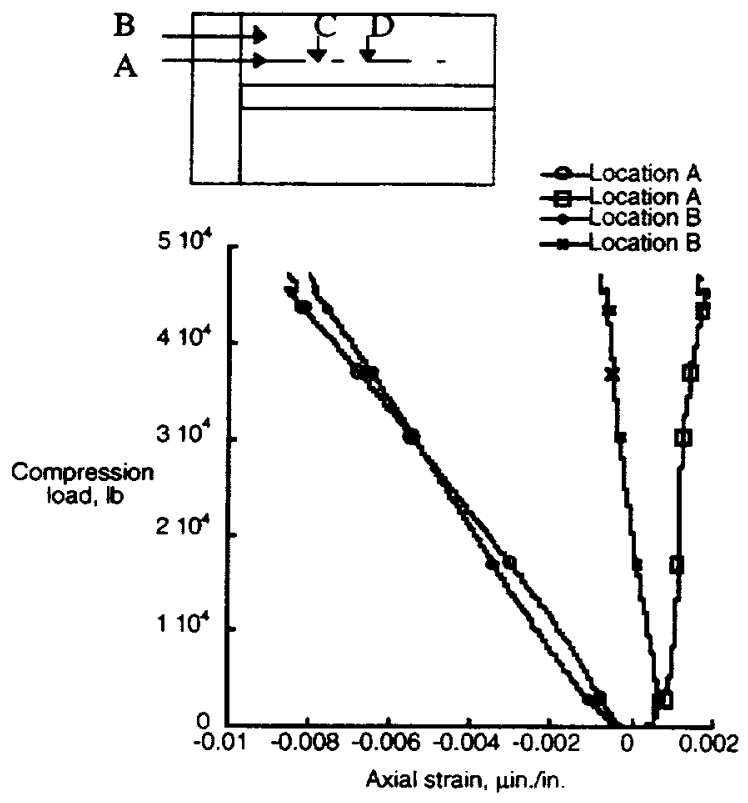

a. Specimen longitudinal direction.

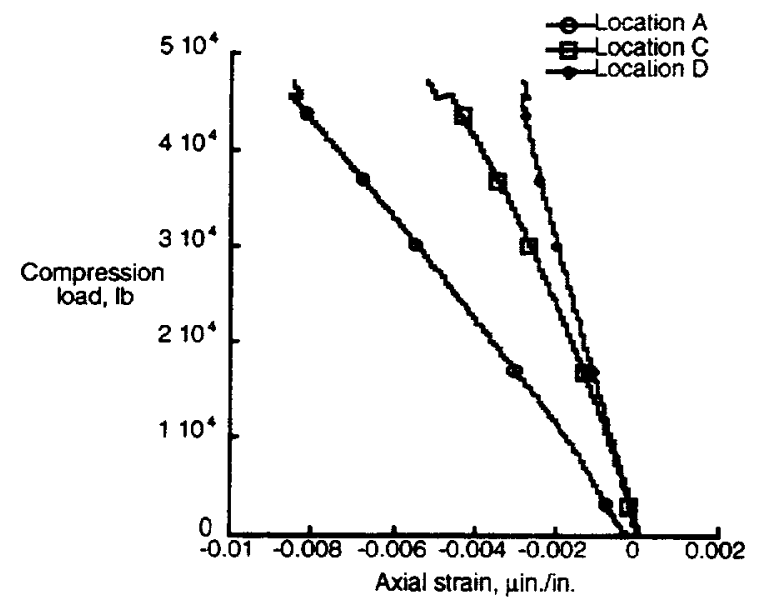

b. Specimen width direction.

Figure 9. Typical axial strain distributions on the skin surface for stiffener termination Concept 1.

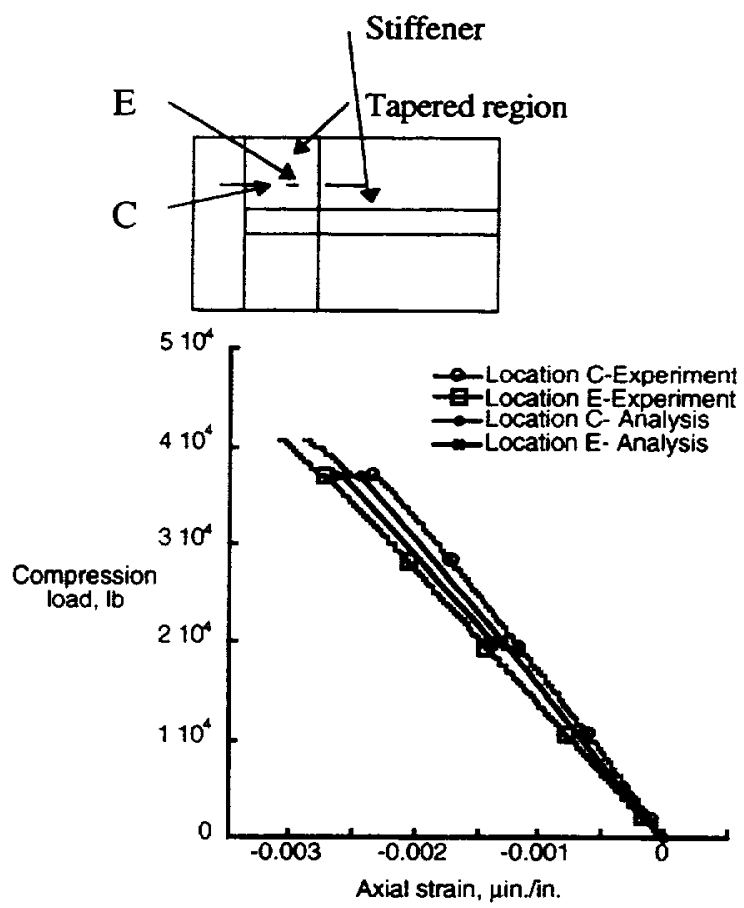

Figure 10. Comparison of experimental and analytical axial strain results for stiffener termination Concept 2 .

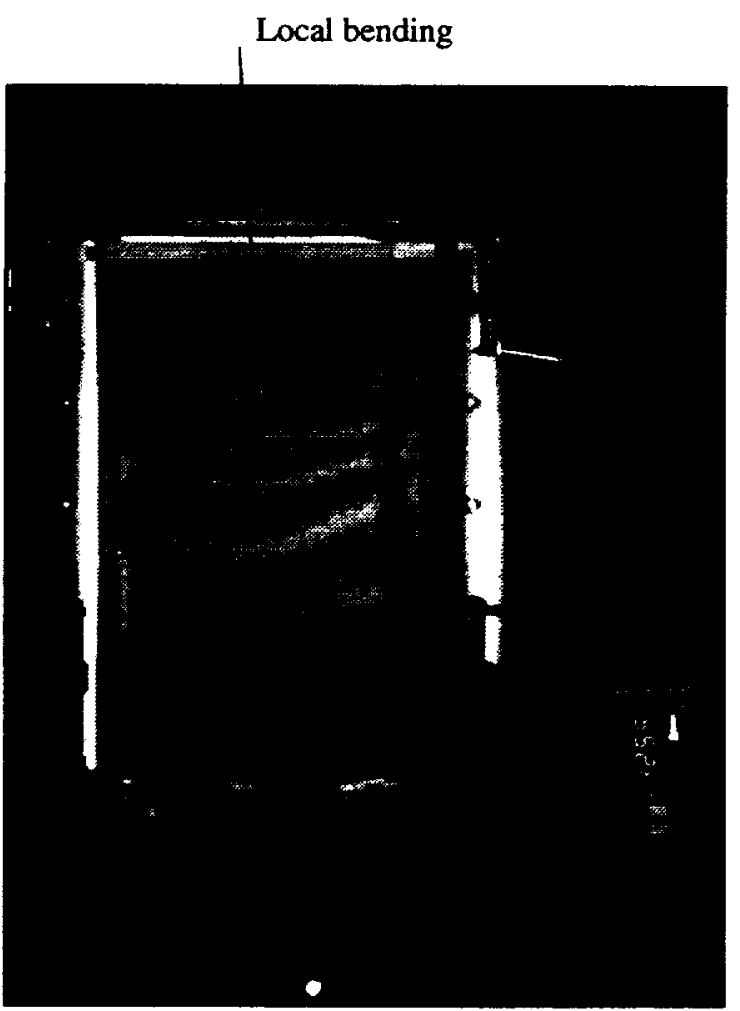

a. Out-of-plane deflection contours.

Figure 11. Continued. 


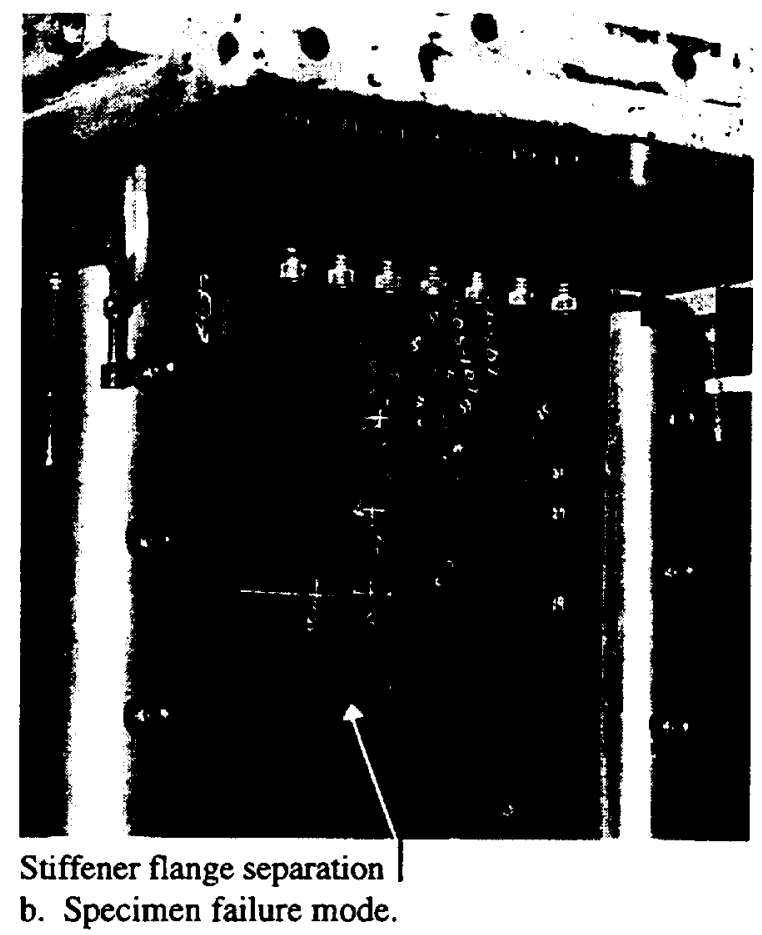

Figure 11. Out-of-plane deflection contours and failure mode of stiffener termination Concept 1.

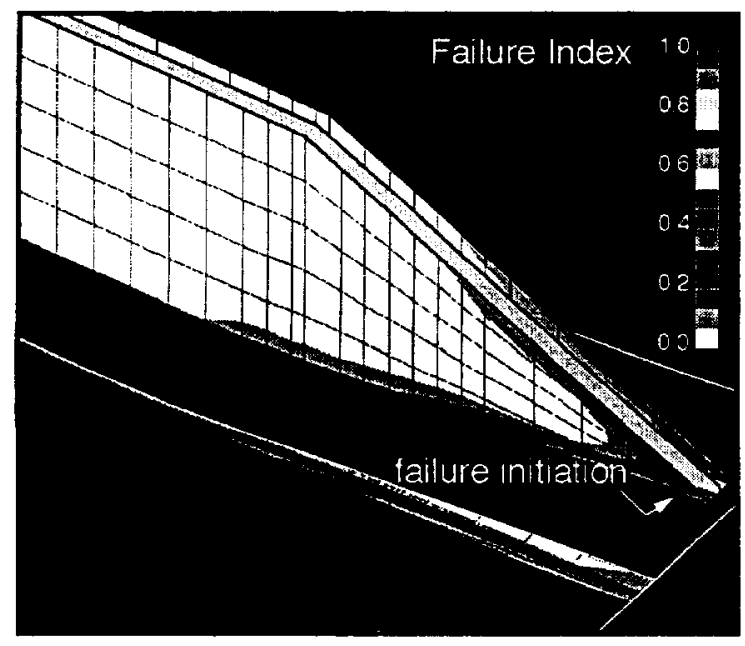

Figure 12. Quadratic failure delamination index results for stiffener termination Concept 2.

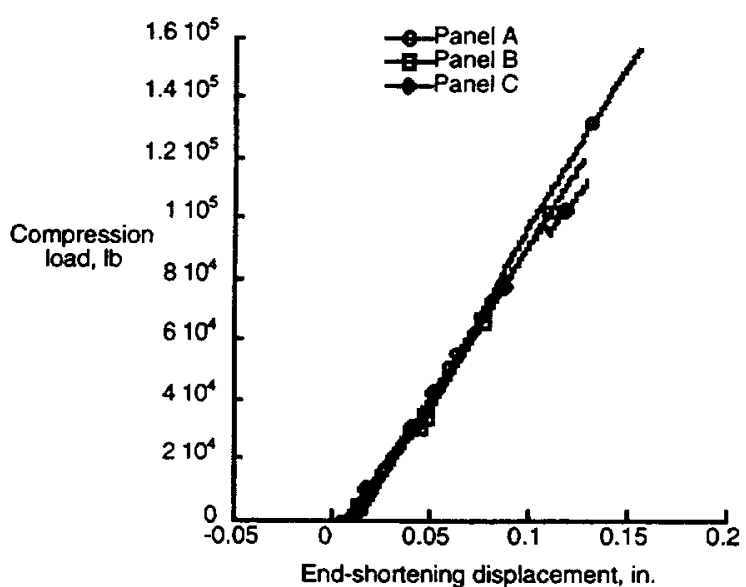

a. End-shortening displacement.

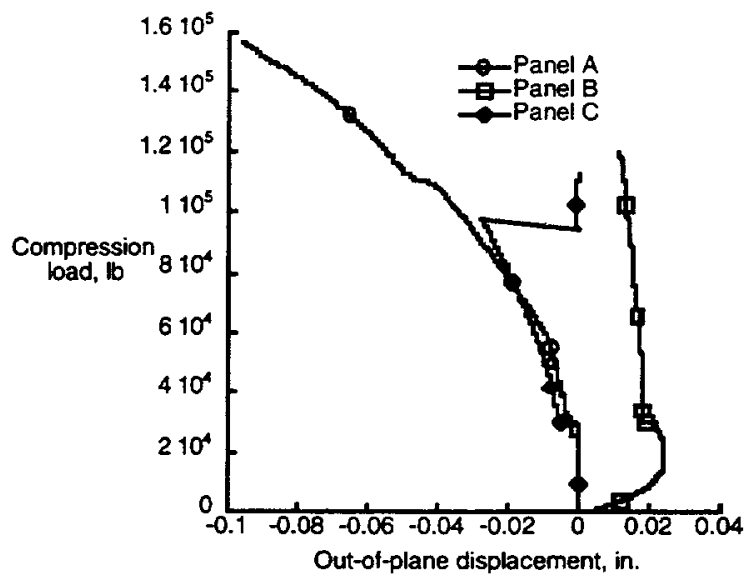

b. Out-of-plane displacement.

Figure 13. Summary of experimental results for threestiffener specimens.
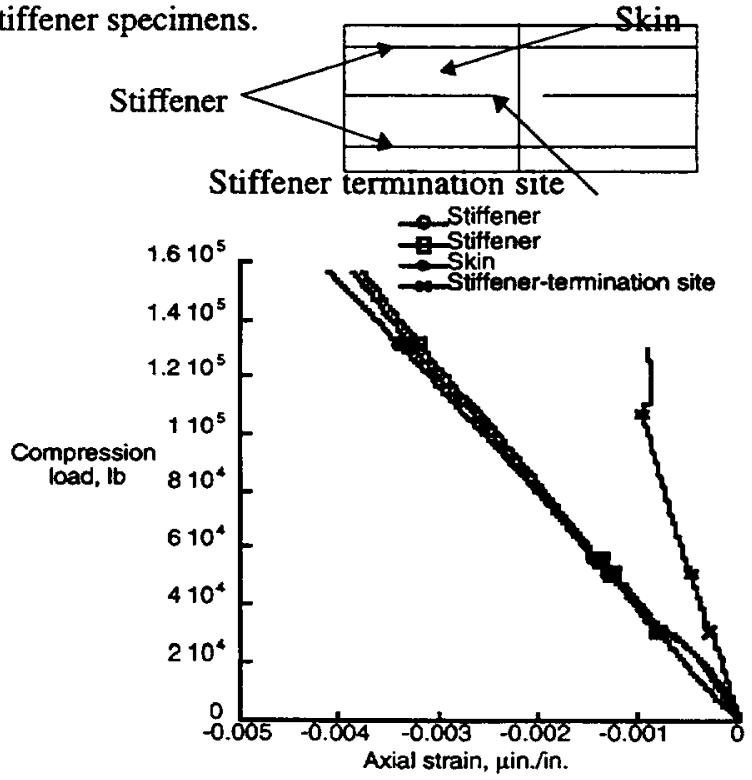

Figure 14. Typical axial strain results for three-stiffener Panel A. 


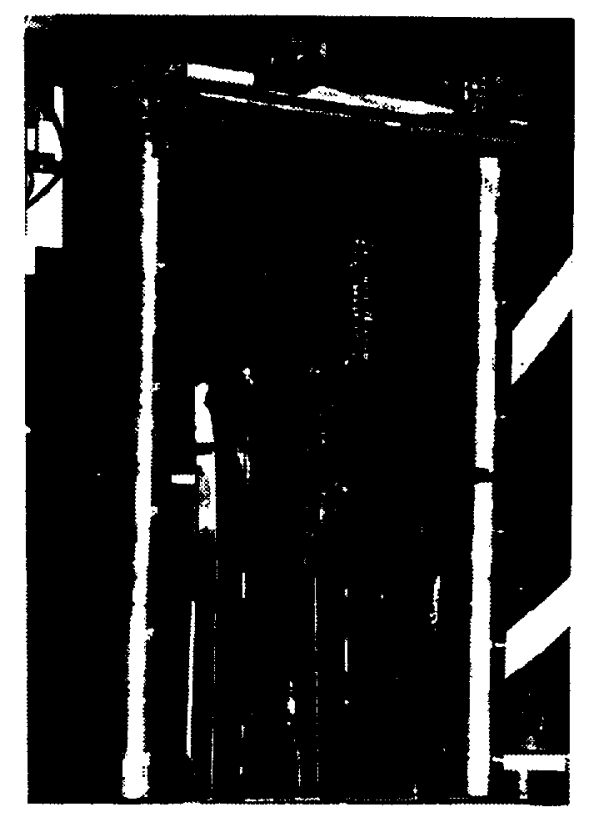

a. Panel A viewed from stiffener side.

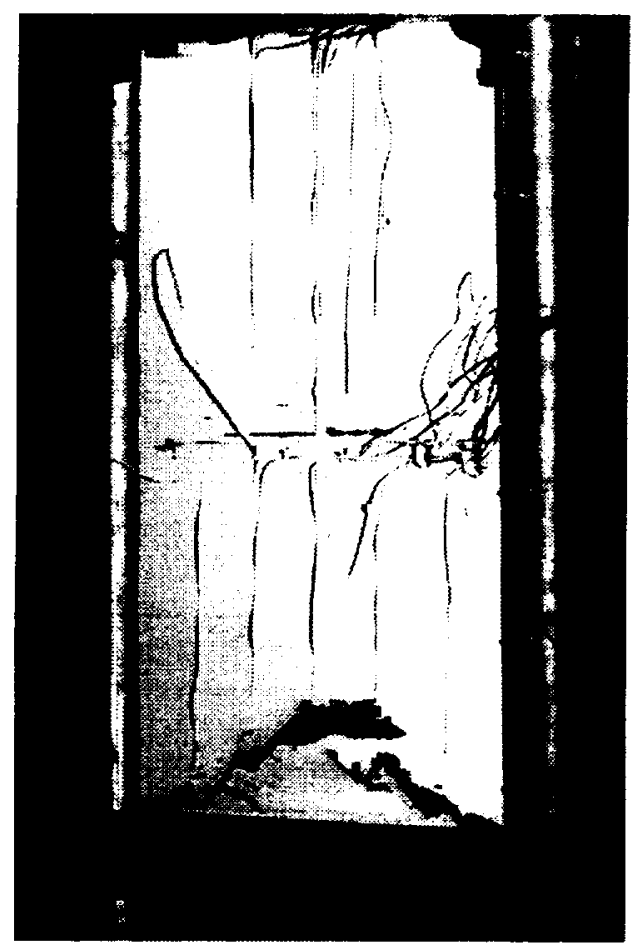

b. Panel viewed from skin side.

Figure 15. Failure mode for three-stiffener Panel A.

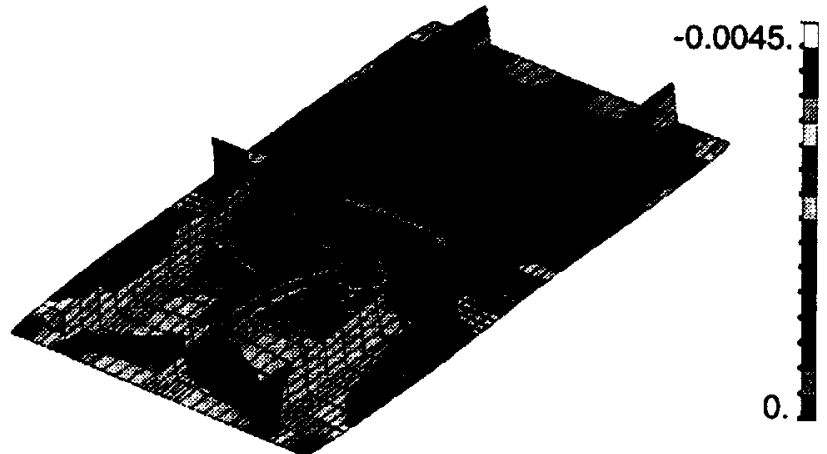

a. Panel B.

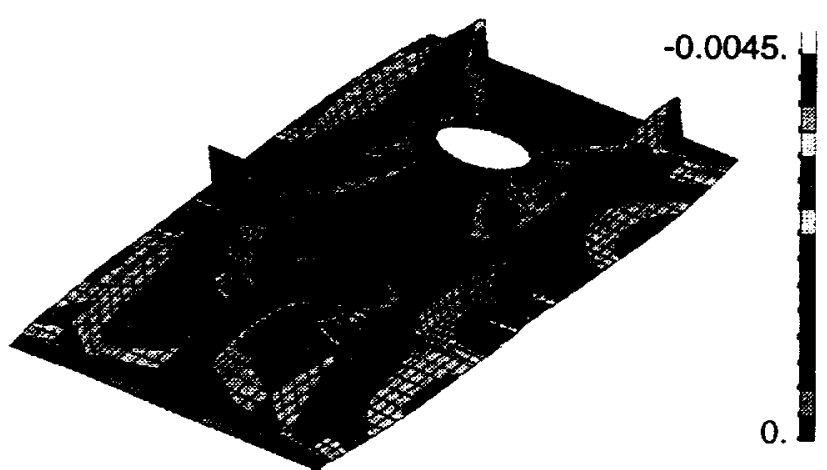

b. Panel C.

Figure 16. Analytical axial strain contours for threestiffener panels with tapered skin.

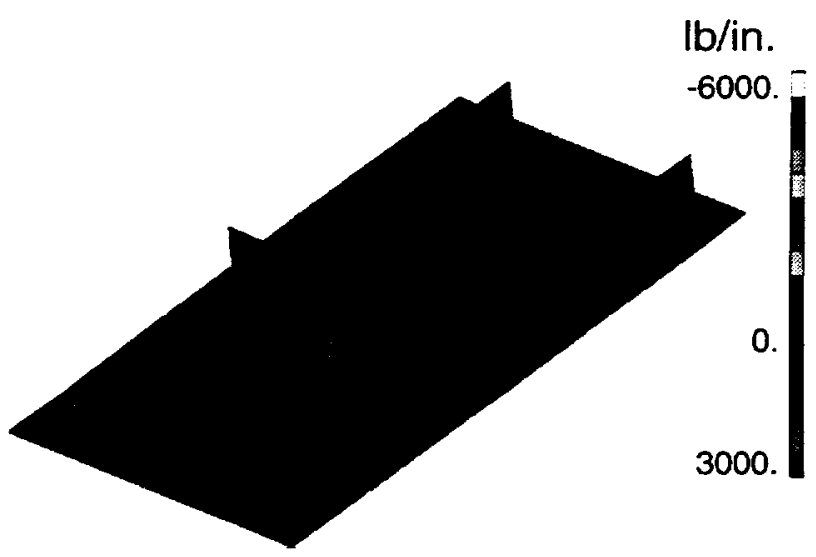

a. Panel B.

Figure 17. Continued. 


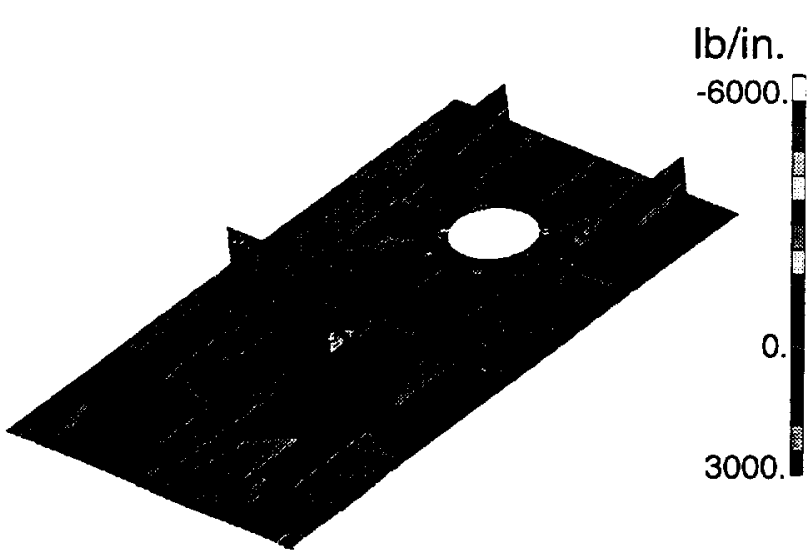

b. Panel C.

Figure 17. Analytical shear stress contours for threestiffener panels with tapered skin.

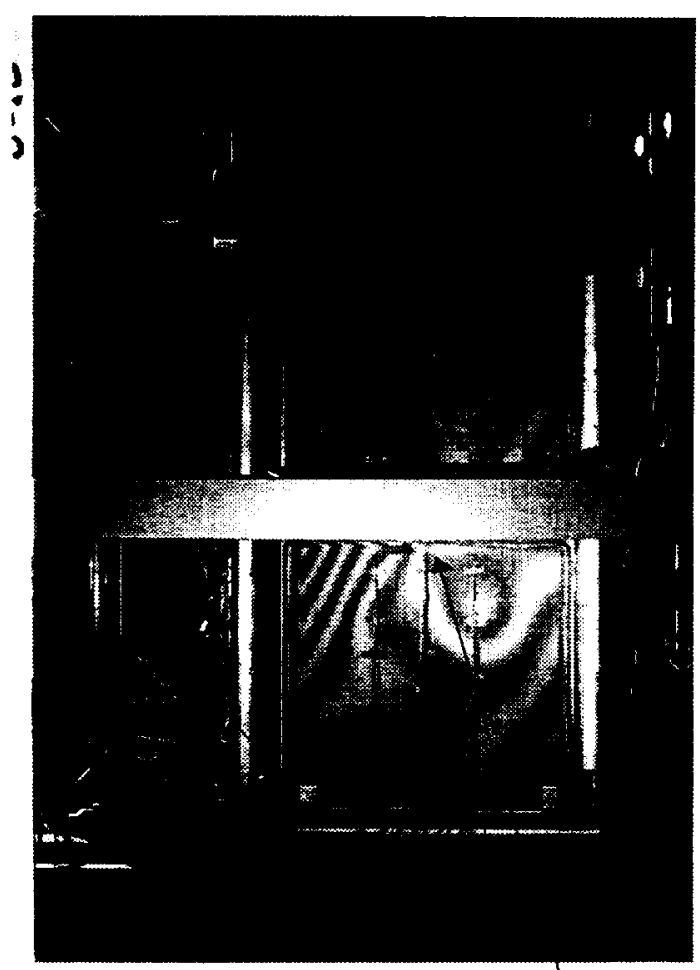

Stiffener termination location

a. Out-of-plane displacement contours at the stiffener termination region.

Figure 18. Three-stiffener Panel C response.

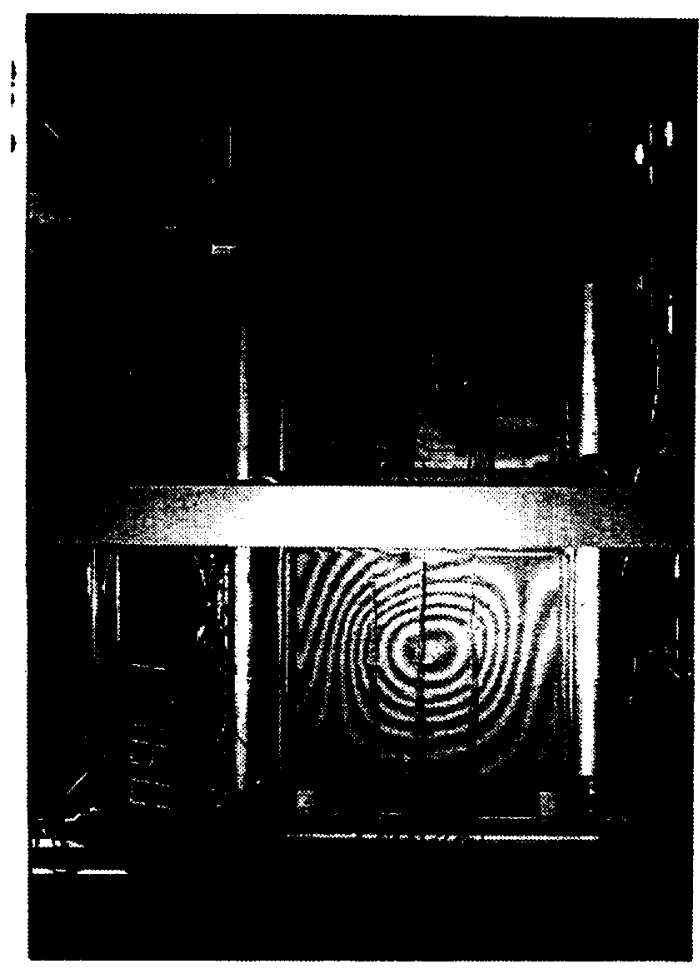

b. Out-of-plane displacement contours for skin with debonded skin reinforcment.

Figure 18. Concluded.
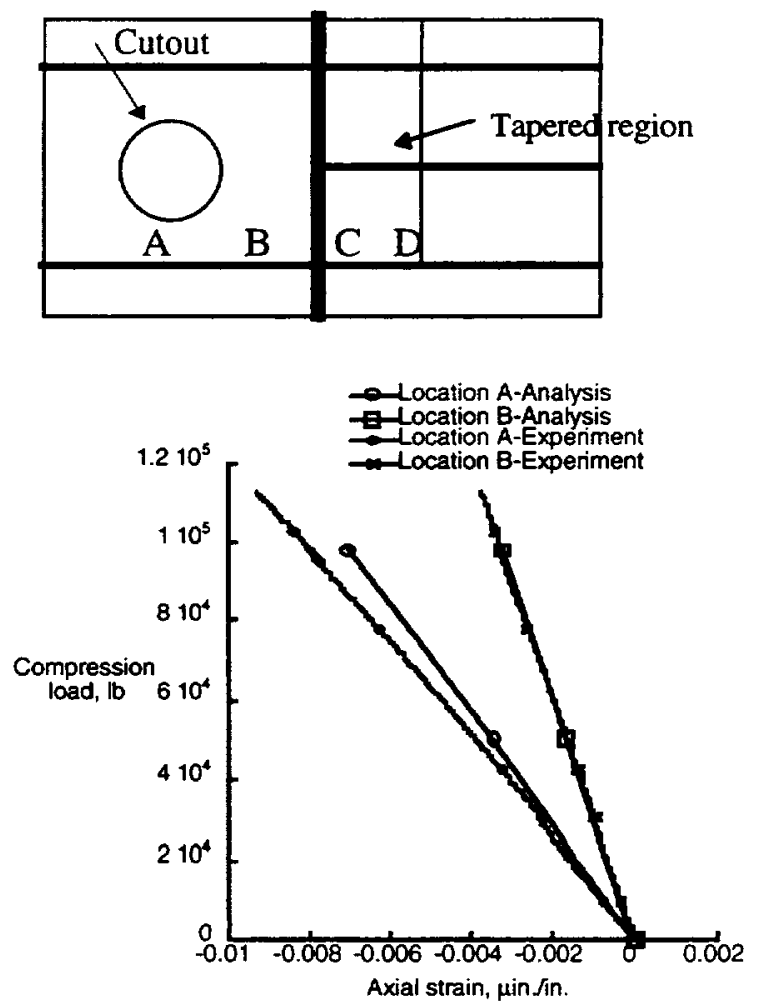

a. Comparison of axial strains at Locations A and B. Figure 19. Continued. 


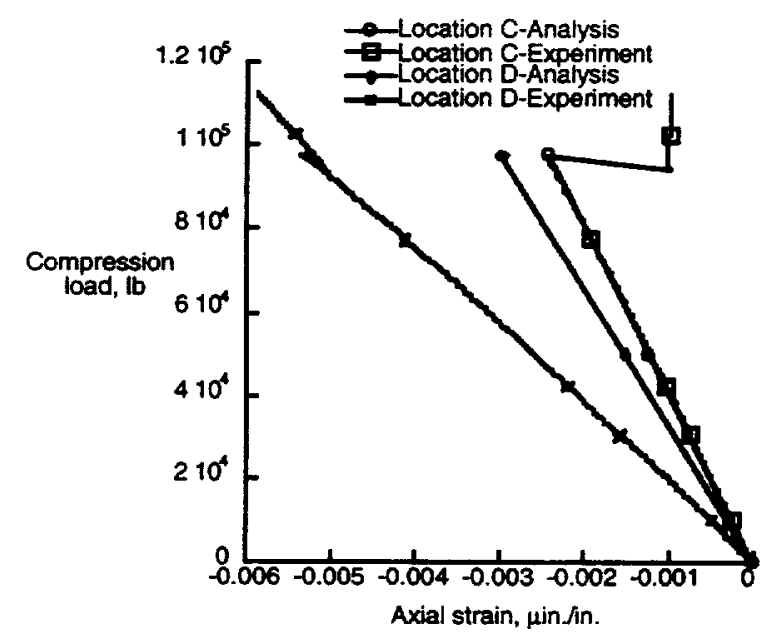

b. Comparison of axial strains at Locations $C$ and $D$.

Figure 19. Summary of axial strain results for threestiffener Panel C. 